\title{
The Design of Banyankole Traditional House: Power Dimensions, Hospitality and Bedroom Dynamics
}

\author{
Emmanuel Mutungi* \\ Department of Art and Industrial Design, Faculty of Vocational Studies, Kyambogo University, Uganda \\ *Corresponding Author: Emmanuel Mutungi, Department of Art and Industrial Design, Faculty of \\ Vocational Studies, Kyambogo University, Uganda
}

\begin{abstract}
This paper analyses the design layout of a traditional Kinyankole house in which the design was meant to promote and strengthen family power dimensions, bedroom dynamics and hospitality. In many societies, culture embodies values, beliefs and customs, it is a social function that brings out the society's identity, solidarity and how traditions and shared values are communicated among members and also preserved. Basing on tacit knowledge, I interviewed five elders about the social connotation and meaning of the Banyankole house design, the material culture items used in the home. I used in-depth informal interviews to gather information that enabled $i$ to provide the explanations for the Banyankole house design. First, $i$ argue that the house design epitomized the power structure in which families and the entire community were governed. Second, the design showed how welcoming and organized the families were. Third, the layout of the bedrooms represented respect and strategy of the bedroom dynamics. I conclude by observing that some aspects of indigenous designs need to be adopted into contemporary designs because the design promoted values and respect among family and community members.
\end{abstract}

Keywords: Bedroom Dynamics, Family Hospitality, Family Power Dimensions, Kinyankole House

\section{INTRODUCTION}

Culture plays an important role in achieving originality and aesthetic value considerations in the design and creativity field (Weggeman, Lammers, \& Akkermans, 2007; European Commission, 2009). In fact, the European Commission (2009) argues that culture is the expression of humanity's creativity that brings out meaning, knowledge, talents, civilization and values of individual groups. As the world becomes one block under globalization, we argue that cross cultural designs will be a required design characteristic before any product penetrates the global market and sustain its visibility there. The fact that production machinery and technology has globally been standardized, cultural uniqueness will be the most identifying character for any successful product. In addition, the emergence of several design approaches that have been recently developed to manipulate various design challenges, continue to narrow down the variety of design concepts on the market. Although contemporary designs are appealing to the user, users do not have any embedded attachment to the designs. Unlike the traditional designs which were based on well-studied frameworks and were part of the community values, contemporary designs are simply accepted on their face value. The case of Banyankole house design is one of such designs that were embedded with a lot of well-studied frameworks that highlighted community values and demonstrated a well-organized society.

The Banyankole are a Bantu speaking group of people living in Western Uganda. They have two main social sub-groups of Bairu (crop growers) and Bahima (cattle keepers). Apart from being referred to as occupants of the Ankole Kingdom in Western Uganda which was a creation of British rule at the beginning of the $20^{\text {th }}$ Century, the Banyankole are believed to have lived in the areas which were favorable for their occupations such as Rwanda, Tanzania, Democratic Republic of Congo and other districts of Uganda. Existing old literature informs us that before 1900, there were several independent kingdoms and chieftainships in the area and Nkore was the strongest of all (Karugire 1971). After the 1900 Buganda agreement which established the protectorate rule in Buganda, other agreements such as the 1900 Tooro agreement and the 1901 Ankole agreement were signed which resulted in the Ankole kingdom. Ankole was created out of merging Nkore a strong kingdom in the area with other small kingdoms and chieftainships such as Igara, Buhweju, Bunyarguru, and other 
small ones in the area. A good synopsis of the area history (Nkore and neighboring kingdoms and chieftainships) is provided by Morris (1962), Karugire (1971) Kirindi (2008) and Kamuhangire (1992). The literature abounds that Ankole was a colonial name given to Nkore because the Baganda agents and their British masters could not pronounce the word Nkore. Ankole was therefore adopted as a name to encompass the merged pre-colonial Nkore and small neighboring kingdoms of Buhweju, Buzimba, Igara, Bunyaruguru and principalities of Mpororo such as Nshenyi, Obwera and Bwishikatwa, which till then were independent polities. It is these diverse kingdoms and polities that were brought together in a loose coalition to form the Kingdom of Ankole. Therefore, the occupants of this kingdom could be interchangeably referred to as Banyankore or Banyankole.

The Banyankole house design represented the power dimensions, hospitality in the family set up and bedroom dynamics. The Banyankole material culture items clearly spelt out each member's responsibility and roles. The houses were temporary built with organic materials, especially flexible trees and thatched with grass. The houses could be kept for as long as the family would stay in one place. The Banyankole never stayed in one place because they kept moving from place to place in search of resources that favoured their livelihoods. The Banyankole lived as either cattle keepers or crop cultivators. The house designs were round and were divided into three main spaces (Figure 1). The spaces included the living room, the sleeping room for the head of the family and his wife and the sleeping room for the children and sometimes where visitors would sleep.
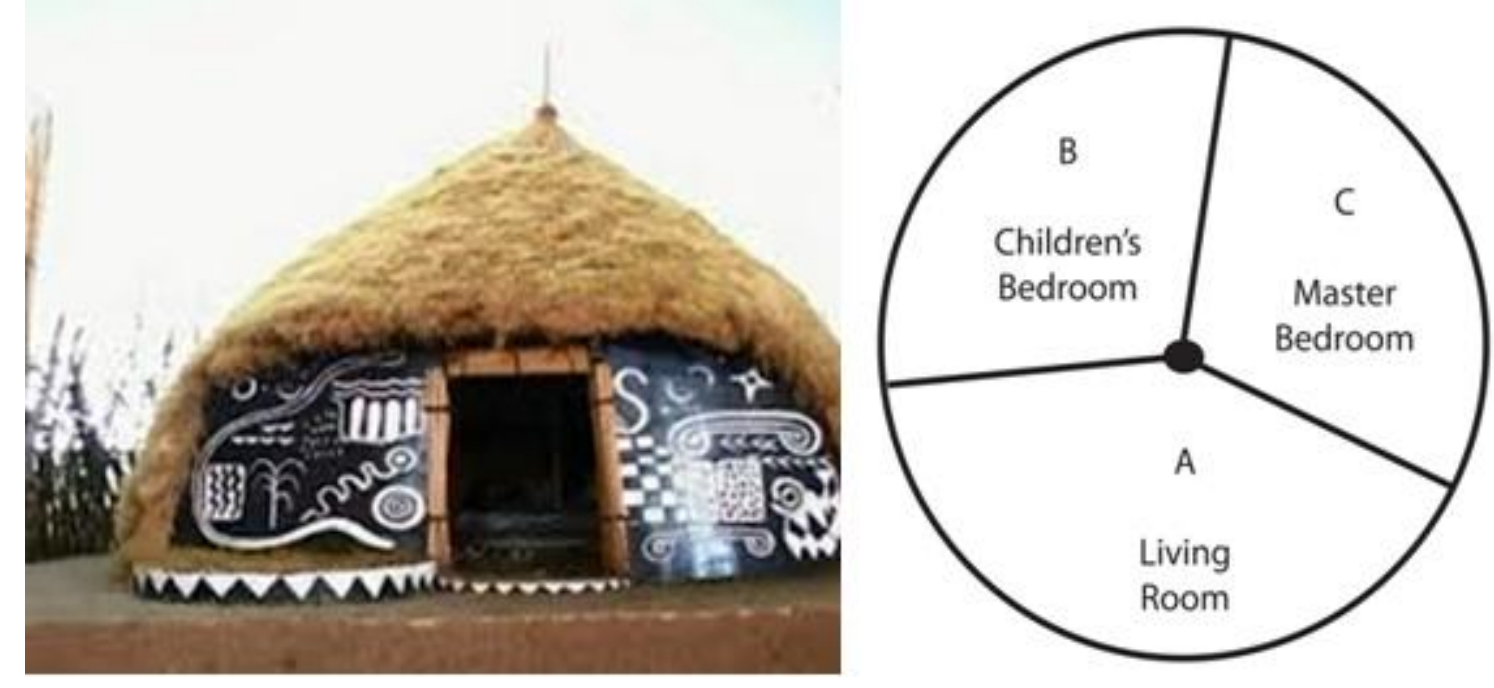

Figure1. Kinyankole house exterior (courtesy of Uganda Museum) and lay out

The first space "A" served as the living room. It was a sitting room, dining and kitchen and sometimes as a pen for newly born calves. Space "B" served as Children's room and sometimes for visitors. Space "C" served as a Master bedroom only used for the husband and wife. Each space was carefully designed to serve its purpose.

\section{Method}

Principally, the study followed a deductive approach, where narratives of five elders in Kanoni and Engari-sya sub-counties in Kazo county Kiruhura district were used to share their tacit knowledge about traditional house design. I adopted this method because it would allow free expression by respondents and was appropriate to generate information for the study. The method was relevant because Niedderer\&Imani (2008) see it as one of the most appropriate means crucial in creative and practice-led disciplines such as the traditional house construction.

I chose not to involve the young people in the study because the youth have been influenced by modern living styles, religious influence and educational systems which could generate biased data. Aware that some aspects of the research, such as bedroom dynamics is not a frequently and freely discussed subject, and that only $20 \%$ of information is explicit, I allowed the study to take an informal deductive approach. Respondents told their story with fewer interruptions unless the interjection was a precursor for a new idea. I allowed free expression because according to Alvesson (2002) cited in Canale(2011) knowledge is becoming an asset and as such it has to be protected and treated carefully because tacit knowledge has an important perspective of development. 
The collection of qualitative data through in-depth interviews enabled me to form an opinion which I used to interpret the house designs. Qualitative data was gathered from in-depth semi-structured face to face interviews and phone calls from five elderly senior members of the community who were purposefully selected. As Saunders et al. (2007) observe that the tools for semi-structured interviews do not necessarily have to follow a particular order because there is no pre-determined order to follow and some questions can vary. Respondents were therefore allowed to freely narrate their stories with minimum interruptions. The checklist that covered different aspects of the research was used, and remained flexible in the manner questions were asked. Respondents led the conversation as I listened. This approach was helpful because it developed confidence and trust within the respondents (Zaltman\& Moorman, 1988).

\section{ReSUlts}

The tacit knowledge collected from the five respondents illuminated several considerations that informed Banyankole house designs. Data from respondents revealed that Kinyankore house designs were based on a framework derived from the activities and roles of each member of the family as well as the entire community. Respondents further revealed that whenever one was constructing a house, several members of the community would participate. It was a collective responsibility in which male adults came together for the good a community.

\subsection{Space A: Living Room}

The living room was designed in such a way to allow different activities to take place in a home. Traditionally, a house did not have fixed doors because the house was considered as part of the kraal. The main gates of the houses were secured with a mihiigo (assorted dry tree branches that were used to close the main entrance of the kraal). The cattle stayed near the house, especially cows that had calves. It was also believed that as cattle rested, their breath was a pre-cursor for sound sleep for their owners. To avoid the cattle from damaging the grass thatched houses, a wooden retainer was usually erected in front of the house. The living room space was divided into the following work stations; Orugyeegye (Milk pot platform), Akarugu (one side of the entrance), and Amahega (the other side of the entrance).

\subsubsection{Orugyeegye (Milk pot platform)}

The spacious design and material culture used in Banyankole houses were not meant to only serve the day-to-day activities in a home, but also helped in identifying distinct characteristics of various community members and to segregate roles in homes. Families perceived indigenous house designs and materials as a means to assign responsibilities, determine maturity, and instill respect in a way a household or community was run. The study respondents informed the researcher that some areas in a house such as orugyeegye (milk pot stand) were significantly important in managing the affairs of the family. This was observed from the position of the orugyeegye and in the manner in which milk pots were exhibited on it. Orugyeegye was located in a central position in a house. The milk pots were also arranged according to their sizes and who used them. The entire arrangement showed the pride of the community, the power dimensions and hospitality of households.

Orugyeegye is traditionally located astride the emwomyoyakanono (centre pole of the house). One of the respondents who was found seated next to orugyeegye attending to her milk pots explained that orugyeegye is a centre of power and a reflection of roles and obligations of each homestead member in traditional Banyankole culture. She recounted that the orugyeegye was located in the middle of a house astride the enyomoy'akanono because it was the main food store where everybody had to be served. Ekyanzikya'nyineeka (the milk pot in which the head of the family was served) was placed next to enyomoy'akanono because nyineeka was a central figure and the head of the family. The other milk pots were then arranged on either side of ekyanzikya'nyineeka following their importance. The milk pot such as one for the wife, children, visitors, and for making ghee and those milk pots without a specific user were displayed on either side the milk pot for the head of the family. The aim was to show the hierarchy of power at home. Respondents observed that the woman's special place in the home was next to the orugyeegye because that is where she could serve the milk to her family. This was very important because through it, women were able to participate in family matters. On the other hand, orugyeegye was also a place from which women traditionally drew their respect and contributed to the affairs of their family. In the first place, women were able to know how much milk was collected each day, which cow had more milk and which cow had the best milk for making ghee or 
serving to visitors. It was next to orugyeegye where women spent most of their time and effectively administer to their families. If one was not appreciated by the woman in the home, one would fail to get milk to drink because only women were allowed to handle all activities surrounding the orugyeegye.

\subsubsection{Amahega (Fire place)}

On one side of the entrance, there was amahega (the cooking place). This is the place where food was prepared or roasted and where water for washing hands was boiled. The fire place was installed with traditional adjustable cooking stones which were adjustable so as to accommodate different sizes of cooking pots unlike the modern cooking stoves that instead have different sizes of plates or burners. Above the fireplace there was orutaraor obugamba (a drying rack) which was designed for preservation and preparation of food items. Orutara was made out of pieces of wood which were joined using fibres from tree barks. Several items such as millet, cassava, meat, grasshoppers were dried on the orutara. More so, bananas were put on orutarato ripen. The space that remained between the fireplace and the house wall was used for keeping the pots especially for mingling millet meal and boiling meat.

\subsubsection{Akarugu (one side of the entrance)}

This was one side of the entrance of the house which was reserved for newly born calves. Whenever the cows produced, the calf was kept inside the house opposite the fireplace. It was done so to avoid the calves from being eaten by wild animals, but also to provide warmth for them. The calf would later be transferred to the calf-pen after two or three days. In families of crop cultivators, akarugu was a place where goats and hens used to stay at night. Although this practice was later discouraged as unhealthy, the initial design for keeping animals safe from wild animals cannot be underestimated. In homes where the goats were kept in akarugu, several poles were erected and each goat had its pole.

The rest of the space was a living room for the family members. The design did not encourage the use of chairs. Actually traditionally, the house had two wooden stools. One of the stools was for the head of the family (ekitebe kyanyineka) and the other for special visitors. However, the living room was neatly covered with grass (eyojwa) which was collected by women and young girls from the hills. Various skins would then be placed on top of the grass. It is on this neatly done and colorful arrangement (remember the skins had different spots of color) that formed the general design of a Banyankole front space of the house.

\subsection{Space B: Ekitabo Kyanyineka (The Master Bedroom)}

Unlike the modern bedrooms where there is a closet for clothes, the traditional bedroom was almost all occupied by the bed. The difference between the children's room and the master bedroom was the position of the entrance. While the children's room entrance was in the middle of the house, the entrance to the master bedroom was at the side, leaving a small free space. The beds were made of sticks woven together and placed on erected poles. In some cases, the woven sticks were placed on empikye (black soil ant hills). The beds were then covered with a pile of grass well cleaned and sorted. This grass was collected by women, sorted and creatively arranged to create a comfortable bed. Unlike today where men boast of having purchased a good bed or mattress, in the old days, this was a woman's duty and hence, some level of control. On top of the grass, very soft well treated skins were laid. This served as bed sheets.

\subsection{Space C: Ekitabo Kyabaana (Children's Bedroom)}

The children's bedroom covered up the entire room, leaving out no space. From the sitting area, children would go directly to their bedroom. It was also made out of woven sticks erected on poles or empikye, piled grass and several skins placed on top. There was a limit on the age of the children to stay in the bedroom. It is the same bed that visitors would sleep or make shift beds were made in the living room. When children reached the age of 12-13, girls would get married and boys at the age of 16-17 years would build their houses and also get married.

\section{DISCUSSION}

\subsection{On Promotion of Family Power Dimensions}

The Banyankole house was designed with specific spaces and material culture items that demonstrated roles and responsibilities of every member. Furthermore, the power dynamics in a home 
were demonstrated through the manner in which the father's stool was respected, the position of different milk pots on the Orugyeegye, the area where the mother sat, and the position of the spears.

As earlier noted, all milk pots were arranged on the Orugyeegye which was by design located in the centre of the house. The milk pot for the head of the family ekyanzi kyanyineka was placed against the centre pole. The centre pole, according to the architectural design of the Banyankole house was the one that supported the house. The structure was also supported by other small and shorter poles as the dome drops.

The house was made of several ridges - embazi and each ridge was important in achieving the dome shape of the house. In a similar way, the milk pot of the father was placed centrally on the Orugyegye and other milk pots were placed either side of it because the father was the head of the family and was supposed to give the strategic leadership, defend the family members and make decisions that would make his family prosper. The respondents reported sons above sixteen were supposed to build their own houses. In some cases where old boys delayed to build their houses, parents would start getting worried that they might have a problem. This was because by the age of fifteen, it was assumed that the boys could have heard their parents making love which was not a good practice in the African culture. Sex was sacred and for adults only. It was therefore assumed that the boys would gladly welcome the idea of having their own house such that they could immediately be supported to start their own families. On the other hand, the position of the milk pot for the head of the family was as inspiration to young men as they themselves prepare to be heads of their own families.

The traditional house design promoted the role of a mother in a home. The mother's position in the house was an administrative position because of its position at orugyeegye. Women exercised their authority because each member of the family knew that women (mothers) were the custodian of the family welfare. Whenever milk was brought into the house from ishaazi (milking space) the woman would inquire; as follows; Nageeha? The one bringing it would reply as follows nagagaajuya Mugendi, meaning, (whose milk is this?)the one who brought it in would reply; it is for gaaju (that was given to the family by Mugendi). This practice enabled women to take stock of the family herd and especially the production capacity. Having received all the milk and kept it in various milk pots, women were responsible for serving it because no one in the family could, because no one knew which milk was kept for which use. The woman would then serve all the members of the family from the head of the family, the visitors and the children. The mother had powers in this regard because she was the custodian of the source of energy in the home. Unfortunately, the current practice of selling milk has denied women this role and many women are losing their administrative positions in their families. The most affected women are the rural women who depend on the farm produce.

The stool of the father was the most respected item. Whenever the children would innocently sit on it, the mother would rebuke them from using it. It was so sacred because other than sitting on it, the stool was used to bless or curse. Whenever a daughter or son was getting married, the father would sit on the stool to give blessings to his children as they start a new family or he would sit on the stool to receive a daughter in-law and give her blessings. At the same time if the father was annoyed, he would use the same stool to curse whoever annoyed him. This made the stool a significant material culture item in the Banyankole house design.

The design of the house provided a space in the master bedroom for keeping important items such as spears, sticks and other sacred items. Unlike the children's room where the bed stretched from wall to wall, the master bedroom had a space for keeping the items. This can be compared with the bedside drawers of the contemporary bed where in some cases people keep their security equipment. The traditional house had space for keeping the security equipment which was only a responsibility of the head of the family

\subsection{On the Hospitality}

The Banyankole home design was a hospitality venue were families entertained visitors. Traditionally, households were set up on an extended family model where by visitors were expected any time. As such, visitors had a special stool, especially the elders. The interior of the house was covered with eyojwa (soft grass) with well-trimmed animal skins laid on top on which young people and women would sit. The common practice among Banyankole homes was okuterama (vigil). Okuterama was a practice where young men and women would gather at the home of one of the 
families, tell stories and share happy moments. Okuterama was an important activity which compelled families to construct large houses so as to allow in as many people as possible during okuterama. Light and warmth for members was provided by the fireplace which would remain burning in one corner of the house.

In some situations, some families would allow their cows to deliver from the house. This meant that houses had to be well designed to allow such an activity to take place. It also showed how much a Munyankole treasured his cattle. A well-mannered and welcoming family was judged based on the number of cows received as gifts and the number of cows given out to friends. In the Kinyankole tradition, cows are exchanged as gifts between two friends. Many times, friends would mention their intentions to exchange cows during a drinking party at the neighbor's home - entereko, the recipient would officially visit the home of the one giving a cow to be introduced to the family members. This practice of family visiting each other to exchange gifts promoted house designs and increased hospitality in a home.

\subsection{On Bedroom Dynamics}

The Banyankole house design was generally simple, had no ceiling yet well designed to take care of bedroom dynamics. The arrangement of the bedroom was determined by the entrance. The children's bedroom was designed in such a way that it determined the way one would sleep (Figure 2). The entrance to the room was put $3 / 4$ of the room towards the outer wall. The bed covered the entire room. This meant that the first one to enter would extend up to the far end and the next occupant followed. The room was grass thatched with no window and the only light to the room was from the outside or from the fireplace. This arrangement meant that the legs would be put towards the centre pole where there was little light.

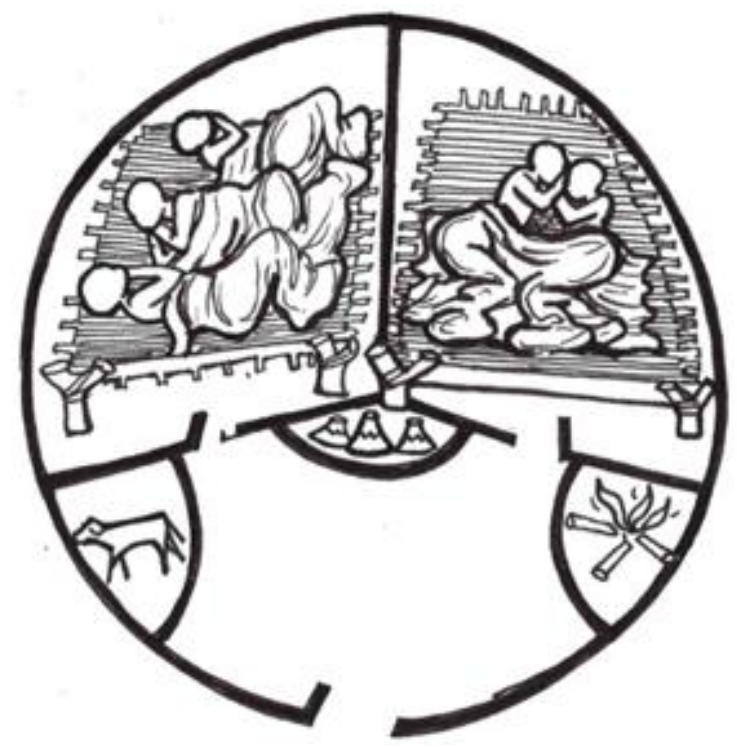

Figure2. Kinyankole house layout showing the bedrooms, platform for milk containers, fire place and place for newly born calves (illustration by Banga Simon)

This was not an accident because the children's head was towards the outer wall of the house and away from the master bedroom. This was helpful because when the parents were making love during the night, it was believed that the children could not hear. Okuhindukaahakitabo (turning on the bed)is a term used when a man engages his wife in sex. The sleeping design in the children's room was therefore meant to reduce the possibility of the children hearing the parent's conversation during the night. It was believed that sex was good, satisfying, and enjoyable during the early hours of the day omwitumbi and that such sex encounter would result into pregnancy. Omwitumbi is the time between 2:30 am and 4:30 am. This was the time recommended for the man to turn on the bed. I posit that this was advocated for because at such a time, children were fast asleep. Unfortunately, in the contemporary societies, men can turn on bed at any time, even during day time, which makes sex less sacred.

The master bedroom was also designed in such a way that it allowed the man engage his wife in an uninterrupted manner. The entrance to the master bedroom was towards the outer wall of the house. 
Unlike the children's bed, which covered the entire space in the room, the master bedroom had a small space where a man kept his spears, sticks and other important artifacts in the home. The bed design extended to the centre pole and it was actually the centre pole that marked the man's position.

The science in the design was that it facilitated effective love making because the man used the pole as a support. The Banyankole have a saying that omucugimubiatiekyahikyaterera (a man who is poor at making love complains that the bed is slippery). In fact, the dynamics of making love were that the man used the centre pole for stability and maintaining the target (Figure3). This was a secret for adults and young boys could not manage turning on the bed because the skins were indeed slippery and one needed to have mastered the science of making love to be able to maneuver without a centre pole. Even when the couple changed the style of turning on the bed from what is now called the missionary style to the akacabari (western jazz), not the western world but probably western Uganda, the man used the centre pole where he rested one leg to be able to apply the western jazz. All in all, the bed room was well designed to facilitate bed room dynamics and was a masterly design of the Banyankole house.

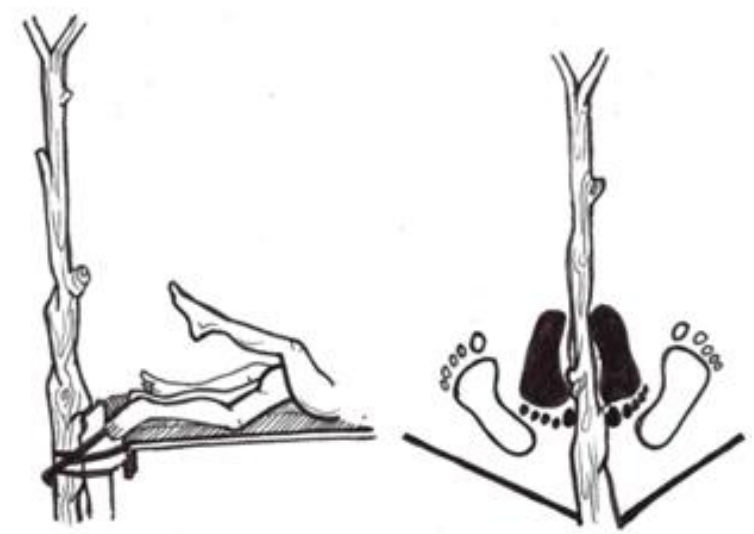

Figure3. Using the centre pole for bedroom dynamics (illustration by Banga Simon)

\section{CONCLUSiOnS}

The Banyankole home design was not only built for accommodation but also as an interaction space. The design promoted family values, respect among society members and a place for co-creation. The success of the family was gauged on the type of a home one had. The design actually did not stop on the house itself but the entire set up of homestead. The design encompassed the space for cows, the pen of calves, the house for the head of the family and other houses in case the family had grown up sons. The narrative of the Banyankole home design gives us a chance to understand the importance of adapting some aspects of indigenous designs into contemporary designs. This practice further, shows that the house design helped in creating a society with high values in terms of behavior respect, productivity and co-creation which should be a guide for contemporary design.

\section{REFERENCES}

[1] Canale, M., D (2011)Tacit Knowledge: How Do We Interpret It? A Qualitative Study of Knowledge Management in Knowledge-Intensive Firms Master thesis Website, School of Economics and Management, Lund University

[2] Faust, B., (n.d.) Implementation of Tacit Knowledge Preservation andTransfer methods Nuklearforum Schweiz, Switzerland

[3] Kamuhangire, R. E. (1993) The Pre-colonial History of the salt lakes region of south western Uganda, C.1000 - 1900 A.D. PhD Thesis Makerere University

[4] Kane H, Ragsdell G and Oppenheim C.(2006) "Knowledge Management Methodologies" The Electronic Journal of Knowledge Management Volume 4 Issue 2, pp 141-152, available online at www.ejkm.com

[5] Karugire, S. (1971) A History of the Kingdom of Ankole in Western Uganda to 1896, Oxford University Press

[6] Kirindi, G.N.P. (2008). History and Culture of the Kingdom of Ankole, Fountain Publishers, Kampala

[7] Morris, H.F.(1962) A History of Ankole, Uganda Literature Bureau

[8] Niedderer, K,. \& Imani, Y,.(2008) Developing a Framework for Managing Tacit Knowledge in Research using Knowledge Management Models, Sheffield Hallam University Research Archive (SHURA) at:http://shura.shu.ac.uk/507/ 
[9] Saunders, M., Lewis, P., Thornhill, A. 2007. Research Methods for Business Students, Prentice Hall

[10] The European Commission (2009) The Impact of Culture on Creativity, A Study prepared for the European Commission (Directorate-General for Education and Culture)

[11] Weggeman, M., Lammers, I,. \& Akkermans, H, (2007) Aesthetics from a design perspective Journal of Organizational Change Management Vol. 20 No. 3, 2007 pp. 346-358 Emerald Group Publishing Limited

[12] Zaltman, G \&amp; Moorman, C (1988). The Importance of Personal Trust in the use of Research, Journal of Advertising Research.

Citation: Emmanuel Mutungi. "The Design of Banyankole Traditional House: Power Dimensions, Hospitality and Bedroom Dynamics" International Journal of Research in Sociology and Anthropology (IJRSA), vol 5, no. 1, 2019, pp. 12-19. doi:http://dx.doi.org/10.20431/2454-8677.0501002.

Copyright: () 2019 Authors. This is an open-access article distributed under the terms of the Creative Commons Attribution License, which permits unrestricted use, distribution, and reproduction in any medium, provided the original author and source are credited. 